\title{
Reticulate phylogeny of gastropod-shell-breeding cichlids from Lake Tanganyika - the result of repeated introgressive hybridization Stephan Koblmüller ${ }^{1}$, Nina Duftner ${ }^{2}$, Kristina M Sefc ${ }^{1}$, Mitsuto Aibara ${ }^{3}$, Martina Stipacek ${ }^{1}$, Michel Blanc ${ }^{1}$, Bernd Egger ${ }^{1}$ and Christian Sturmbauer*1
}

Address: ${ }^{1}$ Department of Zoology, University of Graz, Universitätsplatz 2, 8010 Graz, Austria, ${ }^{2}$ Section of Integrative Biology, University of Texas at Austin,1 University Station, \#C0930, Austin, TX 78712, USA and ${ }^{3}$ Graduate School of Bioscience and Biotechnology, Tokyo Institute of Technology, B21-4259, Nagatsuta-cho, Midori-ku, Yokohama 226-8501, Japan

Email: Stephan Koblmüller - stephan.koblmueller@uni-graz.at; Nina Duftner - nina.duftner@mail.utexas.edu; Kristina M Sefc - kristina.sefc@uni-graz.at; Mitsuto Aibara - maibara@bio.titech.ac.jp; Martina Stipacek - martina-stipacek@gmx.at; Michel Blanc - michel.blanc@education.lu; Bernd Egger - b.egger@uni-graz.at; Christian Sturmbauer* - christian.sturmbauer@uni-graz.at

* Corresponding author

Published: 25 January 2007

BMC Evolutionary Biology 2007, 7:7 doi:10.1/86/147/-2/48-7-7
Received: 12 October 2006

Accepted: 25 January 2007

This article is available from: http://www.biomedcentral.com/l47/-2/48/7/7

(c) 2007 Koblmüller et al; licensee BioMed Central Ltd.

This is an Open Access article distributed under the terms of the Creative Commons Attribution License (http://creativecommons.org/licenses/by/2.0), which permits unrestricted use, distribution, and reproduction in any medium, provided the original work is properly cited.

\begin{abstract}
Background: The tribe Lamprologini is the major substrate breeding lineage of Lake Tanganyika's cichlid species flock. Among several different life history strategies found in lamprologines, the adaptation to live and breed in empty gastropod shells is probably the most peculiar. Although shell-breeding arose several times in the evolutionary history of the lamprologines, all obligatory and most facultative shell-breeders belong to the so called "ossified group", a monophyletic lineage within the lamprologine cichlids. Since their distinctive life style enables these species to live and breed in closest vicinity, we hypothesized that these cichlids might be particularly prone to accidental hybridization, and that introgression might have affected the evolutionary history of this cichlid lineage.

Results: Our analyses revealed discrepancies between phylogenetic hypotheses based on mitochondrial and nuclear (AFLP) data. While the nuclear phylogeny was congruent with morphological, behavioral and ecological characteristics, several species - usually highly specialized shell-breeders - were placed at contradicting positions in the mitochondrial phylogeny. The discordant phylogenies strongly suggest repeated incidents of introgressive hybridization between several distantly related shell-breeding species, which reticulated the phylogeny of this group of cichlids. Long interior branches and high bootstrap support for many interior nodes in the mitochondrial phylogeny argue against a major effect of ancient incomplete lineage sorting on the phylogenetic reconstruction. Moreover, we provide morphological and genetic (mtDNA and microsatellites) evidence for ongoing hybridization among distantly related shell-breeders. In these cases, the territorial males of the inferred paternal species are too large to enter the shells of their mate, such that they have to release their sperm over the entrance of the shell to fertilize the eggs. With sperm dispersal by water currents and wave action, trans-specific fertilization of clutches in neighboring shells seem inevitable, when post-zygotic isolation is incomplete.

Conclusion: From the direct observation of hybrids we conclude that hybridization between distantly related gastropod-shell-breeding cichlids of Lake Tanganyika follows inevitably from their ecological specialization. Moreover, the observed incongruence between mtDNA and nuclear multilocus phylogeny suggests that repeated hybridization events among quite distantly related taxa affected the diversification of this group, and introduced reticulation into their phylogeny.
\end{abstract}




\section{Background}

With an age of 9-12 million years, Lake Tanganyika is the oldest of the three East African Great Lakes and harbors the morphologically, behaviorally and ecologically most diverse cichlid species flock, whose ancestors colonized the swampy and shallow ecosystem of the emerging lake shortly after its formation [1]. The 250 or more cichlid species of Lake Tanganyika have been grouped into a number of mostly endemic tribes, among which the tribe Lamprologini [2] is the most species-rich with $>80$ species. The Lamprologini are the only substrate-breeding endemics in Lake Tanganyika; nearly all of the remaining species are maternal or biparental mouthbrooders. Several of the Lamprologini developed a distinctive life style, in that they live and breed in empty shells of the gastropod species Neothauma tanganyicense, and sometimes Pila ovata, Paramelania spp. and Lavigeria spp. [3,4]. Shellbreeding represents a highly successful evolutionary strategy, and although the behavior arose multiple times during the radiation of the lamprologines [5], most shellbreeding species are members of the "ossified group", a monophyletic group of 28 species characterized by a sesamoid bone within the labial filament [6]. The "ossified group" includes both the smallest $(3.5 \mathrm{~cm})$ and the largest lamprologine $(>30 \mathrm{~cm})$; in shell-breeding species, either both sexes are sufficiently small to fit in gastropod-shells, or the sexes display extreme size dimorphism with dwarf females and males too large to enter the shells [7].

Most shell-breeding species utilize shell-beds aggregated by wave action or individual shells scattered on the lake floor, but males of one species - Lamprologus callipterus collect and pile shells to nests [3]. Some of these shells may already be inhabited by another shell breeder, which thus gets transferred into the L. callipterus nest. Additionally, shell-breeders often colonize these nests actively, such that shell nests and natural shell aggregations often house a densely packed multi-species community of individuals living and breeding in closest vicinity (Fig. 1). Given that large males spawn openly over the mouth of their mate's shell, this concentration of breeding pairs of different species sets the stage for accidental hybridization and hybridization associated with the employment of alternative reproductive strategies [7].

In order to obtain a better understanding of the evolution and pathways of diversification of shell-breeding lamprologine cichlids, we aimed to reconstruct the phylogeny of the "ossified group" of lamprologines by means of sequences of the entire mitochondrial NADH dehydrogenase subunit 2 gene (ND2) and a set of AFLP markers, and investigate the role of past and ongoing hybridization in the diversification of this group of fishes. Morphological data were incorporated in the analyses to infer hybridization partners.

\section{Results and discussion \\ Hybrid speciation reticulates the phylogeny of the "ossified group" of lamprologines}

Reticulate evolution became first apparent in phylogenetic reconstructions based on 1047 bp of the mitochondrial ND2 gene. The phylogeny of the ossified-group lamprologines (Fig. 2A) is largely congruent with previous reconstructions based on different taxon sampling $[5,8]$, subdividing the "ossified group" into 4 - 5 clades depending on the tree-building algorithm used. A linearized tree analysis suggests that the majority of clades arose at a divergence level of about $7 \%$ ( $\mathrm{TrN}+\Gamma$ distances; Fig. 3), which corresponds to major cladogenesis events in other Lake Tanganyika cichlid lineages [9-11] and platythelphusid crabs [12]. Their diversification may thus have been induced by the same environmental factor, most likely by a substantial drop of the lake level during a period of aridification in eastern Africa about 2.5 to 3 million years ago [13].

Despite the strength of the phylogenetic signal and the high resolution of reconstructed species relationships, the mtDNA phylogeny contains several groupings in striking conflict with morphological, ecological and behavioral similarities. Remarkably, all inconsistencies involve gastropod shell breeders. The first pair of eco-morphologically and behaviorally highly similar species resolved in different clades on the mitochondrial tree is Neolamprologus similis and N. multifasciatus (Fig. 2A). Males and females of both species are sufficiently small to enter gastropod shells - N. multifasciatus is the smallest Tanganyikan cichlid known to date $(3.5 \mathrm{~cm})$ - and both species are facultative shell-breeders, which arrange their nests by excavating sand craters around small accumulations of empty shells and live in family groups. The second group of morphologically and behaviorally similar species separated in the mitochondrial phylogeny includes Lamprologus ocellatus, L. meleagris, L. speciosus and N. wauthioni. These species are sexually monomorphic (see Table 1 for more information), small-bodied obligatory shell-breeders with a maximum size of about $6 \mathrm{~cm}$ that prefer areas with low densities of empty gastropod shells. In each species, the males defend territories and hold harems of two to five females for whom they bury shells in a way that only the opening of the shell remains accessible to a resident female [14]. L. meleagris occurs sympatrically with $N$. wauthioni in the north, and with L. speciosus in the south of its distribution range. Despite their morphological and behavioral similarity, each of these four species clusters with different, eco-morphologically very dissimilar, species (Fig. 2A). Although contrasting with phenotypic data, the mitochondrial tree topology receives high bootstrap support, and a monophyletic clade of L. speciosus, L. meleagris, L. ocellatus and N. wauthioni requires at least 56 additional steps in a MP phylogeny $(\mathrm{P}<0.001 ; \Delta-\ln \mathrm{L}=$ 


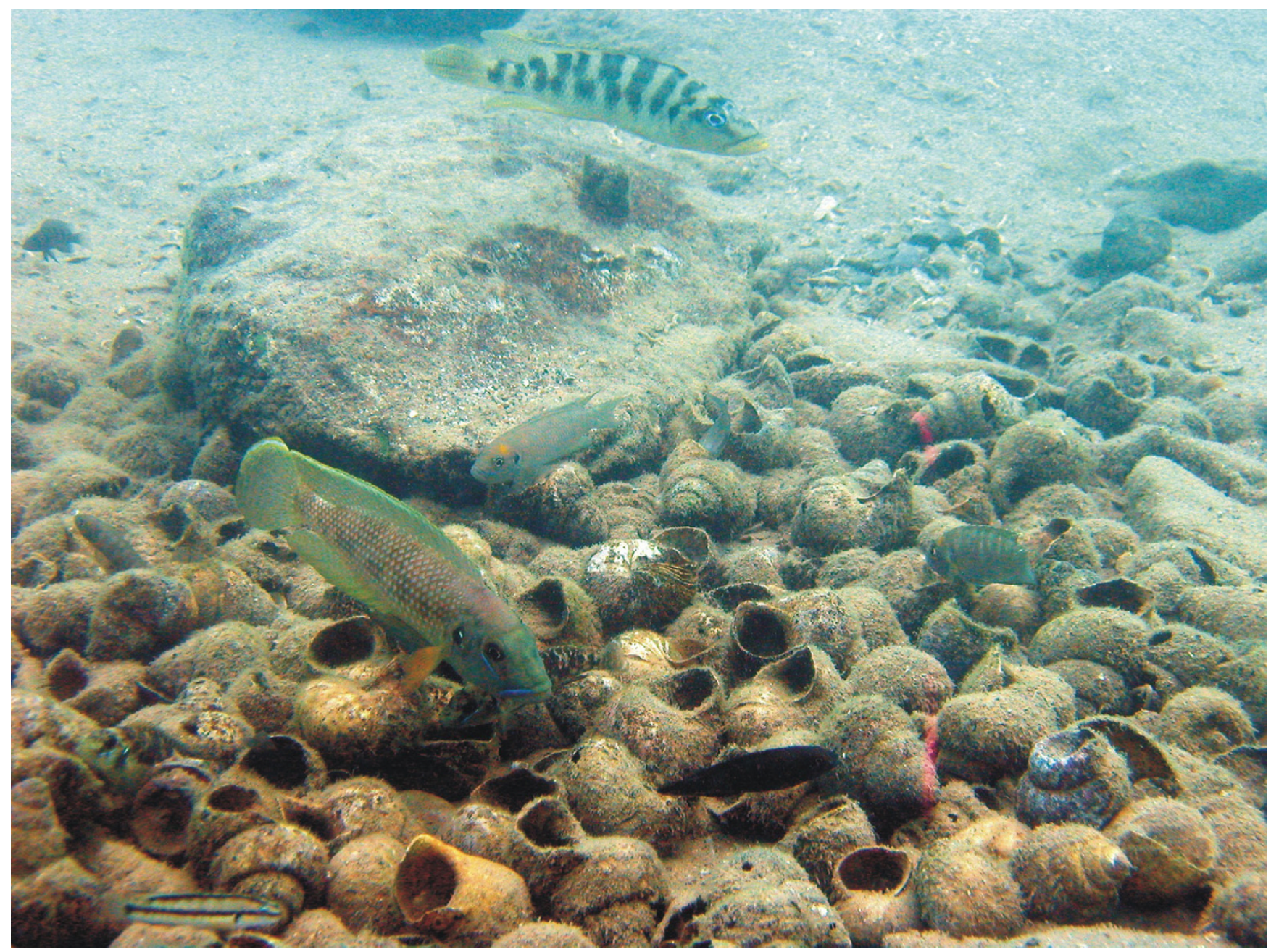

\section{Figure I}

A typical shell-nest constructed by large Lamprologus callipterus males. These aggregations attract different species of obligatory and facultative gastropod-shell-breeders, which consequently live and breed in closest vicinity. The photograph shows individuals of $L$. callipterus, N. calliurus, N. fasciatus and two facultative "non-ossified group" shell-dwellers - Telmatochromis temporalis and $T$. vittatus.

206.84, P<0.001). Forcing N. similis and N. multifasciatus into a monophyletic clade did not significantly increase tree length $(\mathrm{P}>0.05 ; \Delta-\ln \mathrm{L}=24.43, \mathrm{P}>0.05)$, but bootstrap support for the non-sister group relationship between N. multifasciatus and N. similis was high.

In contrast, species relationships inferred from a set of 199 polymorphic AFLP markers were consistent with predictions based on phenotypic trait similarities, as each of the two groups of eco-morphologically similar species was resolved as a monophyletic clade (Fig. 2B). Disparate mitochondrial and nuclear reconstructions were also obtained for the phylogenetic position of another shellbreeding species: Neolamprologus fasciatus clustered with $L$. callipterus and N. wauthioni in the mtDNA-phylogeny, but was placed ancestral to N. multifasciatus and N. similis by
AFLP analyses. A constrained mitochondrial tree congruent with the nuclear placement of $N$. fasciatus would require significantly more evolutionary steps under both parsimony and likelihood criteria (at least 22 steps in MP, $\mathrm{P}<0.001 ; \Delta-\ln \mathrm{L}=97.08, \mathrm{P}<0.001$ in $\mathrm{ML}$ ). Although the current data allow only limited inference of the phylogenetic history of $N$. fasciatus, we can definitely rule out a close affinity to the genus Altolamprologus, which has been suggested due to superficial morphological similarities [14].

Ancient hybridization and ancient incomplete lineage sorting are alternative explanations for the observed discrepancy between the mitochondrial phylogeny and relationships predicted by nuclear markers, phenotypes and behavior. Mismatches among gene trees can result from 


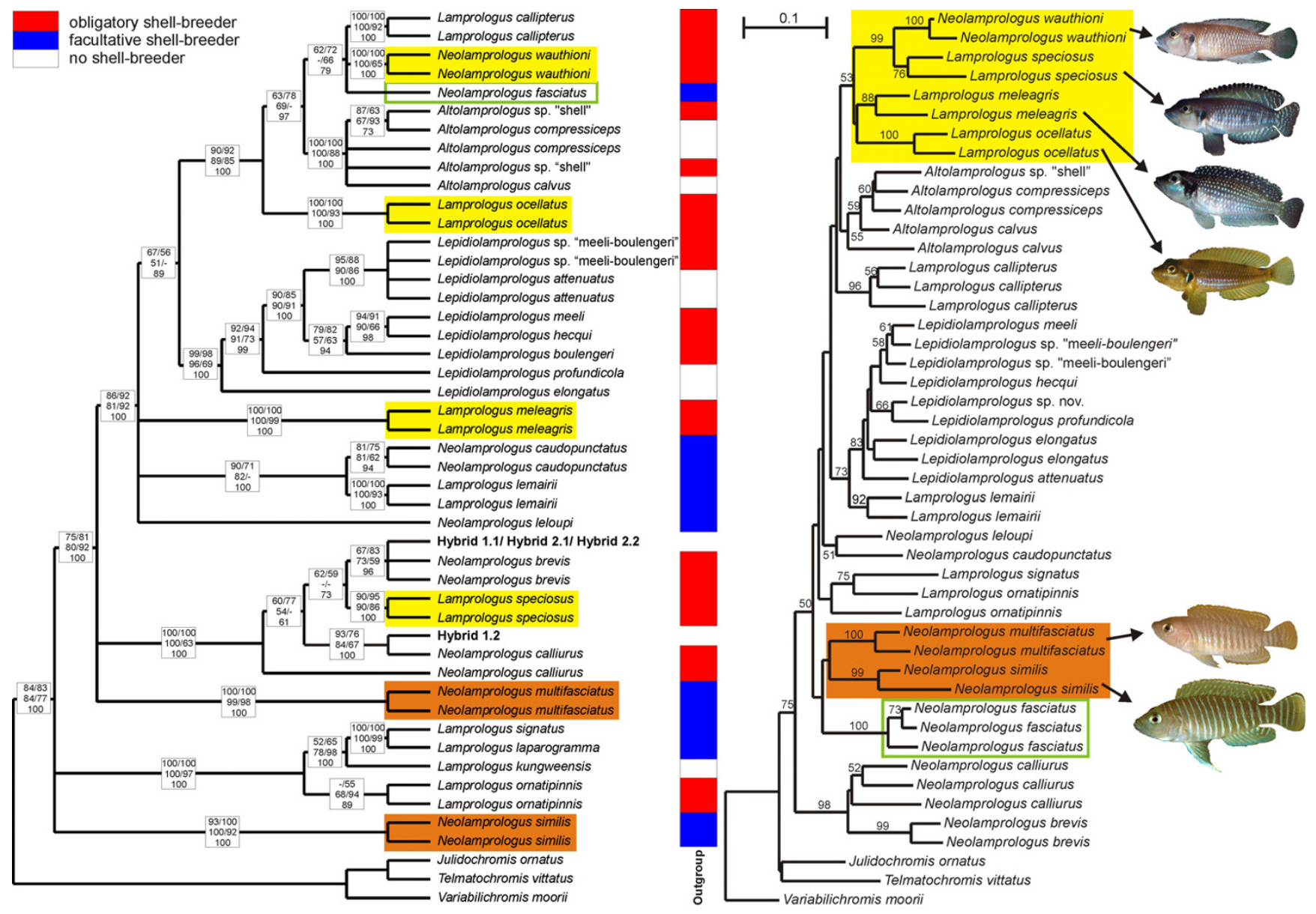

Figure 2

Phylogenetic relationships among the "ossified group" lamprologines. The incongruency between current genus assignments and phylogenetic relationships and the consequent need of a taxonomic revision has been addressed previously [5, 6, 8]. Here, the nomenclature of species in the genus Lepidiolamprologus follows [8] (A) Strict consensus tree of the results obtained from maximum parsimony analysis (MP; 48 most parsimonious trees; tree length, 1390 evolutionary steps; $\mathrm{Cl}$ excluding uninformative characters, $0.6014 ; \mathrm{RI}, 0.7503 ; \mathrm{RC}, 0.45 \mathrm{I} 3$ ), neighbour-joining (NJ), maximum likelihood (ML) and Bayesian inference (BI) based on ND2 sequence data of 48 taxa, representing 27 species of the "ossified group" of lamprologines, four putative hybrid specimens and three outgroup taxa. Boxes on the branches contain bootstrap values obtained from NJ and MP (upper line), ML-bootstrap and quartet puzzling values (middle line), and Bayesian posterior probabilities (bottom line). Only values higher than 50 are shown. Colored bars code for different breeding behaviors. (B) NJ tree based on Nei and Li's distances of the AFLP data of 47 taxa, representing 26 species of the "ossified group" of lamprologines and three outgroup taxa. Bootstrap values $>50$ are shown above the branches. The photographs illustrate the phenotypic similarity between Lamprologus meleagris, L. ocellatus, L. speciosus and Neolamprologus wauthioni, and between N. similis and N. multifasciatus. Colored boxes mark eco-morphologically similar taxa with incongruent positions in the mitochondrial and nuclear phylogenies, as well as the disparate placement of $N$. fasciatus.

the differential assortment of ancestral polymorphisms, when intervals between successive branching events are too short for lineage sorting to be completed within each branch prior to the next split $[15,16]$. This phenomenon occurs, for example, when taxa speciate rapidly during adaptive radiation, and has been repeatedly reported from the cichlid species flocks in the East African Great Lakes $[15,17-20]$. In the mitochondrial phylogeny of the shellbreeding Lamprologini, the taxa affected by inconsistent mitochondrial and nuclear tree topologies (L. speciosus, $L$. meleagris, L. ocellatus and N. wauthioni; and N. multifasciatus and N. similis) have their most recent common ances- 


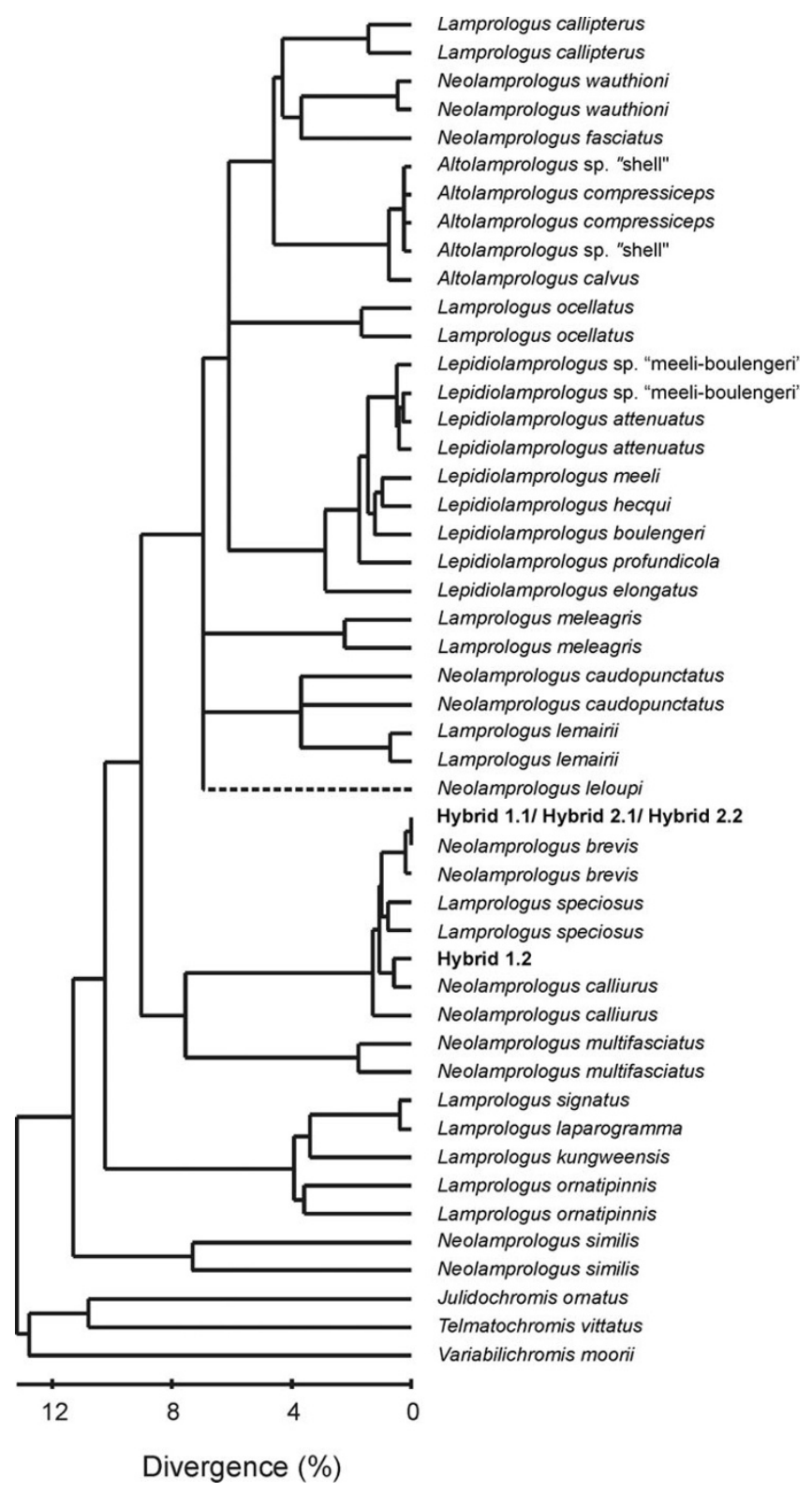

Figure 3

Linearized tree. It is based upon a 1047 bp segment of the mitochondrial ND2 gene applying the substitution model $\mathrm{TrN}+\Gamma$ [46]. After performing a branch length test [49], Neolamprologus leloupi was excluded from the analysis due to a significantly deviating rate of base substitution and subsequently added to the phylogeny according to the results of $\mathrm{NJ}, \mathrm{MP}, \mathrm{ML}$ and Bayesian analysis. The distance values in the scale below the phylogenetic tree correspond to the observed mean sequence divergence using the substitution model $\operatorname{TrN}+\Gamma$.

tor near or at the base of the tree. Long interior branches and bootstrap support for many interior nodes in the mitochondrial phylogeny do not indicate a rapid burst of cladogenesis, such that there may be no major effect of ancient incomplete lineage sorting on the phylogenetic reconstruction.

Nuclear loci coalesce more slowly [21], and are therefore subjected to lineage sorting incongruence over longer periods. The combination of multiple independent loci, as implemented by the AFLP technique, is expected to overcome the problem of idiosyncratic lineage sorting at individual loci [22-24]. Additionally, the species relationships suggested by our AFLP data are supported by phenotypic and behavioral similarities, which makes it unlikely that the AFLP clades result from stochastic lineage sorting rather than reflecting actual relationships.

We contend that the incongruence between the mitochondrial phylogeny and multiple nuclear markers, phenotypes and behavior is best explained by ancient introgressive hybridization events. Furthermore, it is possible that hybridization was directly associated with the speciation of L. meleagris, N. wauthioni, L. speciosus, and N. multifasciatus (Fig. 4), and perhaps also N. fasciatus. Species status according to the biological species concept [25] of the presumed hybrid taxa is supported by sympatric occurrences of $L$. meleagris with L. speciosus in the south and N. wauthioni in the north of its distribution range, and the lake-wide, continuous distribution of $N$. fasciatus.

Although published mitochondrial phylogenies of the mouthbrooding tribes encompass representative species samples [[9-11,26,27], and unpublished data), striking incongruencies with behavioral, ecological and morphological data were detected only in the tribes Tropheini $[26,28,29]$ and Eretmodini [30]. In the tropheine genus Petrochromis, the incongruence was explained by parallel evolution of distinct eco-morphotypes [26], whereas disparate mitochondrial placements of color morphs and species in the tropheine genus Tropheus $[28,29]$ and in the tribe Eretmodini [20] were attributed to introgressive hybridization after secondary admixis. In contrast, diversifying hybridization has been proposed in studies of the substrate breeding Lamprologini, including a role of introgressive hybridization in the speciation of Neolamprologus marunguensis [31] and of Lepidiolamprologus nkambae, a non-shell-breeding member of the "ossified group" of lamprologines [8]. Our results with the shell-breeding lamprologines provide a further example of potential evolutionary consequences of introgressive hybridization in another guild of lamprologine cichlids.

In two instances, species were resolved non-monophyletically. Altolamprologus calvus was paraphyletic in relation to A. compressiceps in the AFLP tree, and Lepidiolamprologus sp. "meeli-boulengeri" was paraphyletic with respect to $L$. meeli in the AFLP tree, while the two taxa were placed in different clades by the mitochondrial sequences. The tax- 
Table I: Life history traits of the species assigned to the „ossified group" of lamprologines.

\begin{tabular}{|c|c|c|c|}
\hline species & Shell-breeding & parental care & mating system \\
\hline Altolamprologus calvus & no & MG & monogamy? \\
\hline Altolamprologus compressiceps & no & MG & harem \\
\hline Altolamprologus sp. "shell" & obligatory & $?$ & $?$ \\
\hline Lamprologus callipterus & obligatory & MG & harem \\
\hline Lamprologus kungweensis & no & MG & monogamy \\
\hline Lamprologus laparogramma & facultative & MG & monogamy \\
\hline Lamprologus lemairii & facultative & MG & harem \\
\hline Lamprologus meleagris & obligatory & MG & harem \\
\hline Lamprologus ocellatus & obligatory & MG & harem \\
\hline Lamprologus ornatipinnis & obligatory & MG & harem \\
\hline Lamprologus signatus & facultative & MG & monogamy \\
\hline Lamprologus speciosus & obligatory & MG & harem \\
\hline Lepdiolamprologus attenuatus & facultative* & BG & mono(bi)gamy \\
\hline Lepidiolamprologus boulengeri & obligatory & MG & monogamy? \\
\hline Lepidiolamprologus elongatus & no & BG & mono(bi)gamy \\
\hline Lepidiolamprologus hecqui & obligatory & MG & $?$ \\
\hline Lepidiolamprologus kendalli ${ }^{+}$ & no & BG & monogamy? \\
\hline Lepidiolamprologus meeli & obligatory & MG & harem \\
\hline Lepidiolamprologus nkambae ${ }^{+}$ & no & BG & monogamy? \\
\hline Lepidiolamprologus pleuromaculatus $^{+}$ & facultative & MG & harem \\
\hline Lepidiolamprologus profundicola & no & MG & harem \\
\hline $\begin{array}{l}\text { Lepidiolamprologus sp. "meeli- } \\
\text { boulengeri" }\end{array}$ & obligatory & MG & harem \\
\hline Lepidiolamprologus sp. nov & no & $?$ & $?$ \\
\hline Neolamprologus brevis & obligatory & MG & harem \\
\hline Neolamprologus calliurus & obligatory & MG & harem \\
\hline Neolamprologus caudopunctatus & facultative & BG & monogamy \\
\hline Neolamprologus fasciatus & facultative & MG & harem \\
\hline Neolamprologus leloupi & facultative & BG & monogamy \\
\hline Neolamprologus multifasciatus & facultative & MG & monogamy? \\
\hline Neolamprologus similis & facultative & MG & monogamy? \\
\hline Neolamprologus variostigma ${ }^{+}$ & no & $?$ & $?$ \\
\hline Neolamprologus wauthioni & obligatory & MG & harem \\
\hline
\end{tabular}

Note: In all species males grow slightly larger than females, but there are only five species - Lamprologus callipterus, Lamprologus lemairii, Lamprologus ornatipinnis, Neolamprologus calliurus, Neolamprologus fasciatus - exhibiting extreme sexual size dimorphism with males growing to at least the double size of females.

MG, maternal guarding; BG, biparental guarding.

${ }^{+}$, species is not included in this study.

*, Lepidiolamprologus attenuatus is too large to enter empty gastropod-shells. Thus, this species occasionally deposits its eggs on the outside of the shell; after hatching fry is transferred into the shell.

Information on the species listed is based on [3, 4, 14, 63-65].

onomy of these species is not well resolved, in that populations with intermediate phenotypes and phenotypic divergence across geographic distances have not yet been adequately addressed (Schelly, pers. comm.). The here identified incongruence between the phylogenetic and current taxonomic resolution must not be dismissed as a possible consequence of persistent ancestral polymorphism in the genetic data, but pinpoints a need for more detailed taxonomic and molecular genetic work on these taxa.

\section{Ongoing hybridization among "ossified group" lamprologines}

Evidence for past hybridization affecting the evolutionary history of the "ossified group" of lamprologines obviously raises the question whether there is also evidence for ongoing hybridization among shell-breeding cichlids. Indeed, within a small area of suitable habitat containing several L. callipterus nests in southern Lake Tanganyika (near Wonzye, Zambia), we collected four specimens that could not be identified to species level but were clearly lamprologine cichlids. Although lamprologines hybridize readily in captivity, this is the first proof of viable natural hybrids in Lake Tanganyika. Mitochondrial sequences determined that the mothers of the hybrids were members of the N. brevis/N. calliurus - clade (Fig. 2A). Hybrid phenotypes and data from six microsatellite loci suggested that two of the hybrids were sired by L. callipterus and the other two by N. fasciatus (Fig. 5A). Morphological similarity indices (Fig. 5B), and a principal component analysis 


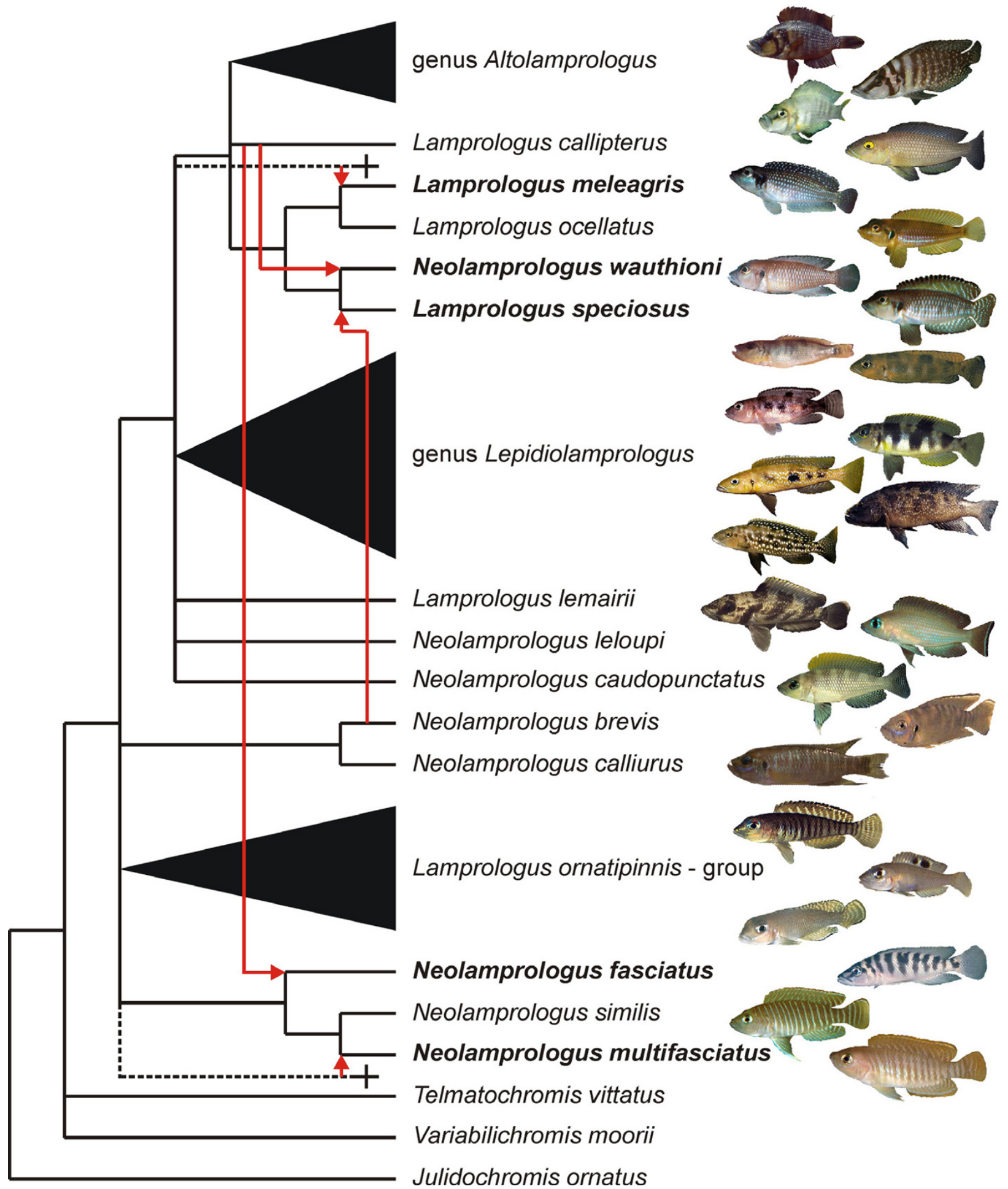

Figure 4

Reticulation of the species phylogeny by hybrid speciation. A strict consensus of mitochondrial and nuclear phylogenies was constructed from the subset of species that was assumed to have undergone bifurcating speciation. The inferred hybrid species (indicated in bold) were added according to their positions in the nuclear phylogeny. Stippled branches indicate hypothesized, now extinct lineages; red arrows indicate the direction of introgression of the mitochondrial genome into the hybrid species. Photographs show the large degree of morphological diversity in the ossified-group lamprologines. 
of morphometric and meristic measurements (Fig. 5C) further supported the phenotypically and genetically inferred identity of the parental species. Furthermore, territorial males of the two putative paternal species $L$. callipterus and $N$. fasciatus are too large to enter empty shells (see Fig. 1), and release their sperm over the entrance of their mate's shell to fertilize her eggs. Dispersion of sperm into adjacent shells by water currents and wave action can bypass prezygotic isolation between species sharing a shell-bed, and result in trans-specific fertilization and hybridization, when post-zygotic isolation is incomplete.

Within the lamprologines, the inferred hybridization partners are only distantly related, as the split between the mitochondrial lineages including $N$. brevis/calliurus and the lineage containing $L$. callipterus and $N$. fasciatus is estimated as $3.80( \pm 1.33)-4.58( \pm 1.60)$ million years before presence ( $\operatorname{TrN}+\Gamma$ distance, $9.08 \pm 1.33 \%$; gammacorrected amino acid distance, $4.44 \pm 1.55 \%$ ) based on a molecular clock for the ND2 gene of cichlid fish [11]. The two N. fasciatus hybrids and one of the L. callipterus hybrids shared a mitochondrial haplotype, whereas a different haplotype was detected in the second $L$. callipterus hybrid (Fig. 1). Hence, the four hybrid individuals represent at least three independent hybridization events between the genetically and morphologically highly divergent species, suggesting that hybridization among shell-breeding species is not uncommon. Introgressive hybridization is commonly associated with loss of diversity through extinction or homogenization of species [3234 ], and the maintenance of species integrity in the face of hybridization suggests that introgression between lamprologine species is constrained by low hybrid fitness. Accidental hybridization among shell-breeders is independent of prezygotic species barriers and unresponsive to reinforcement of pre-mating isolation, such that hybridization rates may not decrease over long divergence times despite possible costs through reduced hybrid fitness.

\section{Conclusion}

Compared to plants [35], the role of hybridization in speciation and diversification in animals has been demonstrated in only a few examples [36] including several cichlid species $[8,31,37,38]$. Our study suggests that shellbreeding lamprologine cichlids experience considerable rates of hybridization without suffering significant erosion of phenotypic diversity. The fixation of introgressed mitochondrial haplotypes reticulated the evolution of this group. Although our data do not provide direct proof of speciation by hybridization, they are consistent with the hypothesis that hybridization might have contributed to the diversification of gastropod shell-breeding cichlids. The high degree of morphological differentiation among lamprologine species entails elevated levels of functional diversity and a strong potential for transgressive segregation in hybrid populations, a condition that allows for the occasional emergence of a successful novel trait combination [38-40]. Stabilization of a recombinant population requires reproductive isolation from the parental species, which has been shown to ensue from ecological separation from both parent species in several cases of hybrid speciation [39]. During the evolutionary history of Lake Tanganyika cichlids, periodical habitat changes associated with lake level fluctuations may have occasionally promoted the stabilization of hybrid populations by providing novel ecological niches, and by precipitating displacements and splits of populations [41], such that geographic separation may have added to or even substituted for ecologically mediated isolation.

\section{Methods \\ Sampling}

Representatives of 31 lamprologine cichlid species, including the outgroup taxa Variablichromis moorii, Telmatochromis vittatus and Julidochromis ornatus, were collected during several sampling trips to Lake Tanganyika from 1992 to 2004 or obtained via the aquarium trade. Fin clips were taken from fresh specimens and preserved in 96\% ethanol. Voucher specimens are available from the authors.

\section{mtDNA}

We analyzed 1047 bp of the entire mitochondrial ND2 gene for 69 individuals, representing 30 sampled species and four putative hybrids. When available, previously published sequences were used $[1,8]$. Total DNA-extraction, polymerase chain reaction (PCR) and chain termination sequencing followed standard protocols $[9,42]$. For both, PCR and chain termination reaction sequencing, we used the primers MET, ND2.2A, TRP [43] and ND2.T-R [11]. Sequences were visualized on an ABI 3100 Sequencer (Applied Biosystems). All sequences are available from GenBank under the accession numbers listed in Additional File 1.

Alignment of DNA sequences was performed using the Sequence Navigator software (Applied Biosystems). Throughout the presented phylogenetic analyses, hierarchical likelihood ratio test statistics were calculated using the program Modeltest 3.06 [44] to evaluate appropriate models of molecular evolution for model based tree reconstructions, and phylogenetic reconstruction based on NJ, ML and MP criteria were calculated with the PAUP* program package (version 4.0b5) [45]. In a first step, a NJ tree including all 69 taxa ssubstitution model $\operatorname{TrN}+\mathrm{I}+\Delta$, [46]; proportion of invariable sites (I), 0.4147; gamma shape parameter $(\alpha), 0.9162\}$ was used to select a representative subset of 48 taxa to minimize computation time for subsequent ML and maximum parsimony (MP) anal- 


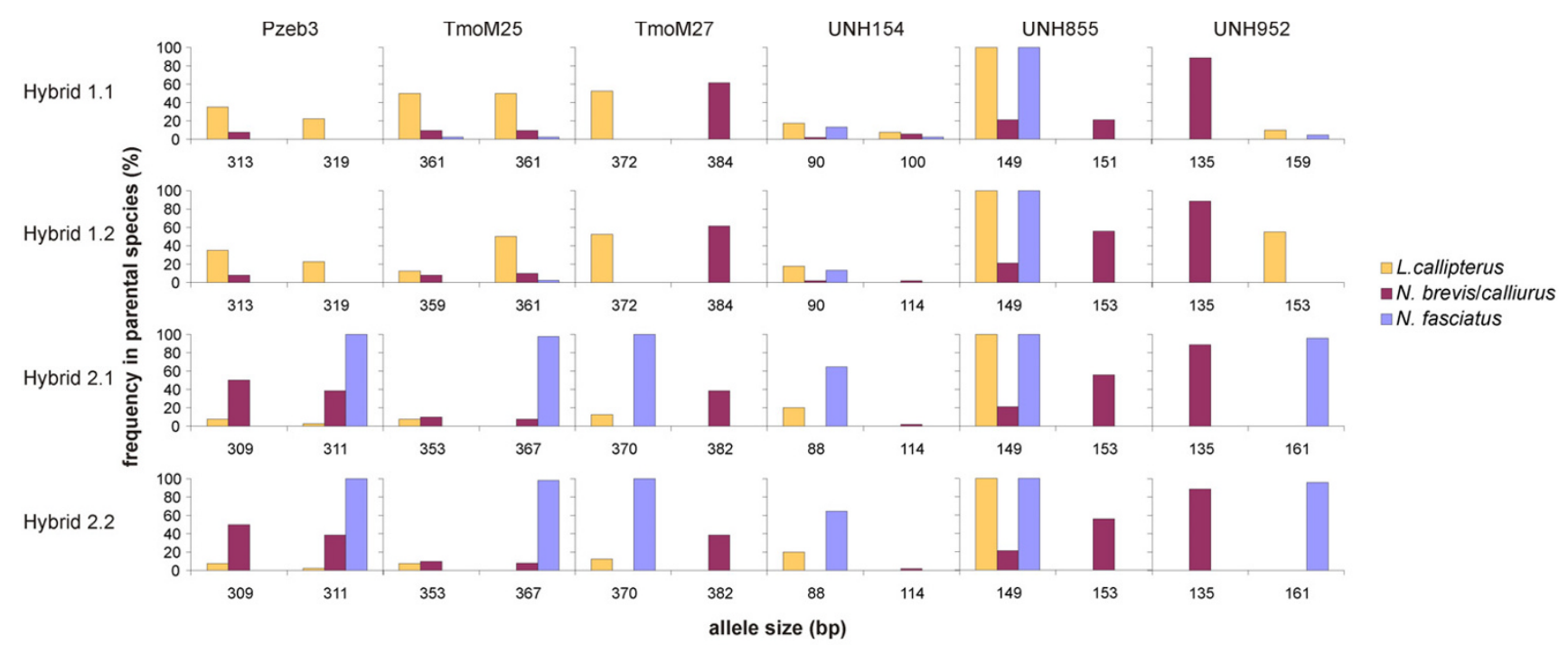

A

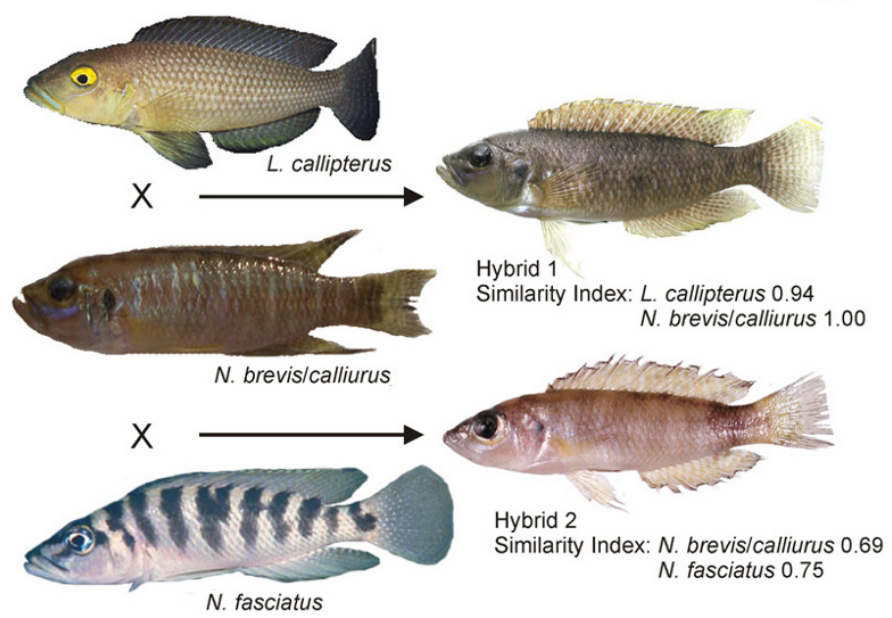

B

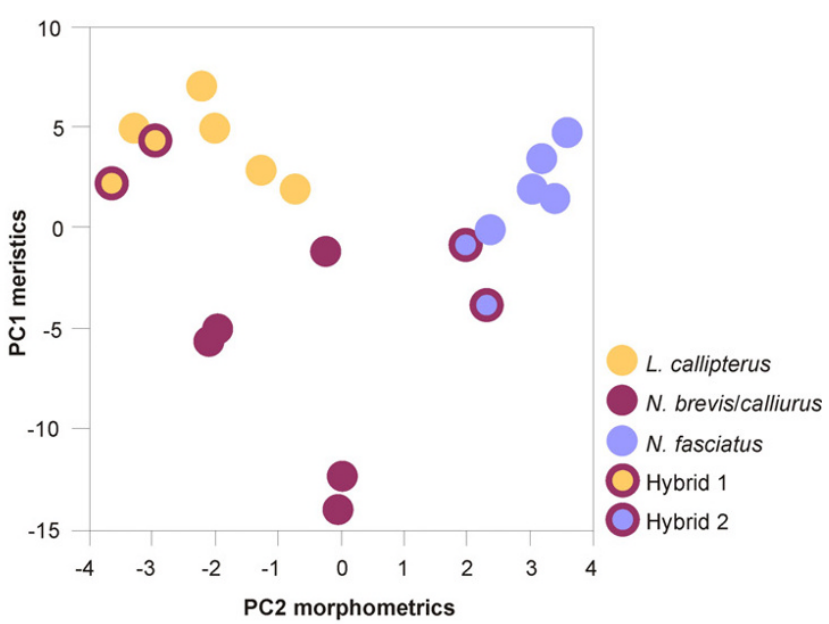

C

Figure 5

Genetic and morphological identification of hybrid parents. Hybrid I.I and hybrid I.2 result from crosses between $L$. callipterus and a member of the clade encompassing N. brevis and N. calliurus, hybrid 2.1 and hybrid 2.2 from hybridization between $N$. fasciatus and N. brevis/calliurus. (A) Allelic composition of the four hybrid specimens at six microsatellite loci. Bars indicate alleles detected in hybrid individuals with bar height proportional to the frequencies of these alleles in each of the putative parental species. (B) Pictures of the hybrid specimens and their parental species and similarity indices based on I 3 qualitative morphological characters demonstrate the intermediate phenotype of the hybrids. Hybrid individuals originating from the same species pair do not differ phenotypically, and only one individual of each hybrid type is shown. (C) Principal component analysis based upon 13 morphometric and 8 meristic measurements place hybrid individuals with the inferred paternal species.

ysis. The reduced data set was then used for NJ and ML analyses (substitution model $\operatorname{TrN}+\mathrm{I}+\Delta ; \mathrm{I}, 0.4083 ; \alpha$, 0.8659 ; base frequencies: A, 0.2530; C, 0.3531; G, 0.1308; $\mathrm{T}, 0.2630$ ), and for MP tree searches with transitions at third codon positions weighted 3:1 with respect to transversions, based on the estimated transition/transversion (TI/TV) ratio of 2.9627. Transversions at third codon posi- tions of fourfold degenerate amino acids were weighted 2:1 with respect to transitions, according to the estimated TI/TV ratio of 2.1140. Synonymous transitions at first positions of leucine codons were treated like transitions at third codon positions. Bootstrapping (1000 pseudo-replicates for NJ and MP; 100 pseudo-replicates for ML) and quartet puzzling [47] (25 000 random quartets) were 
applied to estimate support of the obtained topologies. Phylogenetic relationships were also estimated by a Bayesian method of phylogenetic inference using MRBAYES 3.0b4 [48]. Posterior probabilities were obtained from a 1,000,000 generation Metropolis-coupled Markov chain Monte Carlo simulation (four chains; chain temperature, 0.2 ) with parameters estimated from the data set. Trees were sampled every hundred generations and the first $10 \%$ of all trees were excluded as burn-in to allow likelihood values to reach stationary.

To derive a relative dating of diversification events in the "ossified group" of lamprologines, we computed a linearized tree, using the program LINTRE [49]. To test for constancy of the rate of base substitution among all taxa we performed a branch length test implemented in the program LINTRE based on $\operatorname{TrN}+\Delta$ distances $(\alpha=0.2841)$. Neolamprologus leloupi showed a significantly deviating substitution rate at the $1 \%$ level and was therefore excluded from the calculation of a clock-constrained tree. Mean and standard deviation of average pairwise $\operatorname{TrN}+\Delta$ distances were calculated to achieve a relative dating of diversification events. Since no fossil record is available as calibration point for the "ossified group" of lamprologines, a molecular clock for the cichlid ND2 gene based upon gamma corrected amino acid distances [11], calculated with the program TREE-PUZZLE 5.0 [50], was applied to obtain absolute datings for cladogenesis events.

The significance of differences between alternative tree topologies was evaluated by Kishino-Hasegawa tests [51] and Shimodeira-Hasegawa tests [52] under maximum parsimony and likelihood criteria, respectively.

\section{AFLPs}

For AFLP fingerprinting, whole genomic DNA was extracted from 47 specimens representing 25 species of the "ossified group" of lamprologines and the three outgroup species Julidochromis ornatus, Telmatochromis vittatus and Variabilichromis moorii applying proteinase $\mathrm{K}$ digestion followed by protein precipitation with ammonium acetate and ethanol precipitation of DNA. Restriction digestion of $100 \mathrm{ng}$ of genomic DNA was performed in a total volume of $50 \mu \mathrm{l}$ using $0.5 \mu \mathrm{l}$ MseI (10 units/ $\mu \mathrm{l}$, New England Biolabs), $0.25 \mu \mathrm{l}$ EcoRI (200 units/ $\mu$ l, New England Biolabs), $5 \mu$ l enzyme buffer $(10 \times), 0.5 \mu \mathrm{l}$ BSA $(100 \times)$ and high performance liquid chromatography (HPLC) water, and incubation for three hours at $37^{\circ} \mathrm{C}$. For ligation of adaptors, $1 \mu \mathrm{l}$ EcoRI-adaptor $(50 \mathrm{pmol} / \mu \mathrm{l})$, $1 \mu \mathrm{l} \mathrm{MseI-adaptor}(5 \mathrm{pmol} / \mu \mathrm{l}), 1 \mu \mathrm{l} \mathrm{T} 4$ ligase buffer, $0.2 \mu \mathrm{l}$ T4 DNA ligase and $6.8 \mu \mathrm{l}$ HPLC water were added to the product of the restriction digestion and incubated over night at $37^{\circ} \mathrm{C}$. The ligation products were subsequently diluted to $180 \mu \mathrm{l}$ using HPLC water. PCR was carried out in two steps as recommended by [53]. Preselective amplifications were performed with $3 \mu$ l of the diluted ligation product, $0.4 \mu \mathrm{l}$ each of EcoRI and MseI preselective primers $(10 \mu \mathrm{M}), 2 \mu \mathrm{l} 10 \times \mathrm{MgCl}_{2}$ buffer, $2 \mu \mathrm{l} 10 \times \mathrm{dNTP} \operatorname{mix}(10$ $\mu \mathrm{M}$ ) and $0.6 \mu \mathrm{l} \mathrm{Taq}$ DNA polymerase (5 units/ $\mu \mathrm{l}$, BioTherm $^{\mathrm{TM}}$ ) in a final volume of $20 \mu \mathrm{l}$. The preselective primers consisted of the adaptor primer sequence with a single selective nucleotide at the 3' end (EcoRI-pre: A, MseI-pre: $\mathrm{C})$. The preselective PCR used the following temperature profile: $2 \mathrm{~min}$ at $72^{\circ} \mathrm{C}$ followed by 20 cycles of $20 \mathrm{sec}$ at $94^{\circ} \mathrm{C}, 30 \mathrm{sec}$ at $56^{\circ} \mathrm{C}$, and $2 \mathrm{~min}$ at $72^{\circ} \mathrm{C}$, then a holding step at $60^{\circ} \mathrm{C}$ for $30 \mathrm{~min}$. PCR products were diluted 1:10 for selective amplification. The following recipe was used for selective amplifications with primers extending $3 \mathrm{bp}$ beyond the adaptor sequence: $1 \mu \mathrm{l}$ of the diluted preselective PCR product, $6.3 \mu \mathrm{l} \mathrm{HPLC}$ water, $0.8 \mu \mathrm{l} 10 \times \mathrm{dNTP}$ $\operatorname{mix}(10 \mu \mathrm{M}), 1 \mu \mathrm{l} 10 \times \mathrm{MgCl}_{2}$ buffer, $0.4 \mu \mathrm{l}$ Taq DNA polymerase ( 5 units/ $\mu \mathrm{l}$; BioTherm ${ }^{\mathrm{TM}}$ ), $1 \mu \mathrm{l}$ selective MseI primer $(10 \mu \mathrm{M})$ and $1 \mu \mathrm{l}$ selective EcoRI primer $(1 \mu \mathrm{M})$ labeled with the fluorescent dye FAM. The primer combinations used for selective amplification were: EcoRI-ACA/ MseI-CAT, EcoRI-ACT/MseI-CAT, EcoRI-ACT/MseI-CAA, EcoRI-ACT/MseI-CAC. The temperature profile for the selective PCR was as follows: $2 \mathrm{~min}$ at $94^{\circ} \mathrm{C}$ followed by 10 cycles with $20 \mathrm{sec}$ at $94^{\circ} \mathrm{C}, 30 \mathrm{sec}$ at annealing temperature, which decreased in each cycle by $1^{\circ} \mathrm{C}$ from $65^{\circ} \mathrm{C}$ to $56^{\circ} \mathrm{C}$, and $2 \mathrm{~min}$ at $72^{\circ} \mathrm{C}$. The PCR continued for 25 cycles with $20 \mathrm{sec}$ at $94^{\circ} \mathrm{C}, 30 \mathrm{sec}$ at $56^{\circ} \mathrm{C}$, and $2 \mathrm{~min}$ at $72^{\circ} \mathrm{C}$, followed by a holding step at $60^{\circ} \mathrm{C}$ for $30 \mathrm{~min}$. All amplifications were performed on a GeneAmp PCR system 9700 (Applied Biosystems). Selective amplification products were visualized on an ABI 3100 automated sequencer (Applied Biosystems) along with an internal size standard (GeneScan-500 ROX, Applied Biosystems).

Raw fragment data were analyzed using GENEMAPPER (version 3.7, Applied Biosystems). Presence or absence of peaks (presumed to represent homologous fragments) was scored by eye (in order to avoid misinterpretations inherent to automated fragment scoring) within a range of 100-500 bp and assembled as a binary (1/0) matrix by GENEMAPPER. In a few cases, fragments were scored as missing data when character states could not be determined unambiguously. Matrices from the different primer combinations were assembled into one data set.

A neighbor joining tree based on pairwise genetic distances [54] obtained from the presence/absence matrix was calculated with the program TREECON 1.3b [55]. Bootstrap values from 1000 pseudo-replicates were used as a standard measure of confidence in the reconstructed tree topology. 


\section{Morphological analysis}

Similarity-indices between hybrid individuals and eight possible parental species were calculated based upon the presence or absence of 13 qualitative characters (Additional File 2). Furthermore, a principal component analysis based upon 13 morphometric (Additional File 3) and 8 meristic (Additional File 4) characters [56,57] in the four hybrids and the presumed parental species was performed ( $n=5$ individuals per species). Since the first principal component of the morphometric dataset proofed to be mainly influenced by the standard length, it was not used for analysis. Thus, we plotted PC1 of the meristic data against PC2 of the morphometric data. Loading factors are depicted in Additional Files 5 and 6.

\section{Microsatellites}

Microsatellite markers were used to support morphological inferences of species identity of the parents of the collected hybrid individuals. The four hybrid individuals, one to three representatives of 15 species of obligatory and facultative shell-breeding lamprologines and populations of the three candidate parent species (as identified by morphological criteria) were genotyped at six microsatellite loci with low intraspecific variation in lamprologine cichlids (Pzeb3 [58], TmoM25, TmoM27 [59], UNH154 [60], UNH855 and UNH952 [61]; see Additional Files 7 and 8). Populations of the three candidate parental species, Lamprologus callipterus $(\mathrm{n}=19)$, Neolamprologus brevis/calliurus $(\mathrm{n}=24)$ and $N$. fasciatus $(\mathrm{n}=21)$ were sampled at the same locality as the hybrid individuals (Wonzye, S $08^{\circ} 43^{\prime}$, E $31^{\circ} 08^{\prime}$ ). Mitochondrial sequences placed all four hybrid individuals in the clade containing $N$. brevis and $N$. calliurus, which are very closely related and often synonymized since sub-adult individuals of these two species cannot be distinguished in the field (Figs. 2, 3, 4).

Total DNA-extraction and amplification of microsatellites followed standard protocols [62]. Fragments were visualized on an ABI 377 automated sequencer (Applied Biosystems) using forward primers labeled with fluorescence dyes FAM, TET or HEX, and the internal size standard Genescan-500 TAMRA (Applied Biosystems).

\section{Authors' contributions}

SK, ND, KMS and CS designed the study and were involved in sampling. SK, ND, MS, MB and BE carried out the molecular work and the analyses, whereas MA was responsible for the morphological data. SK, ND, KMS and CS contributed to the preparation of the manuscript. All authors read and approved the final version.

\section{Additional material}

\section{Additional file 1}

Species information, geographic origin and GenBank accession numbers of all taxa used for phylogenetic analysis.

Click here for file

[http://www.biomedcentral.com/content/supplementary/1471-

2148-7-7-S1.doc]

\section{Additional file 2}

Matrix of characters used for estimating similarity indices between hybrids and candidate parental species.

Click here for file

[http://www.biomedcentral.com/content/supplementary/1471-

2148-7-7-S2.doc]

\section{Additional file 3}

Morphometric measurements for PCA of hybrids and parental species. Click here for file

[http://www.biomedcentral.com/content/supplementary/14712148-7-7-S3.doc]

\section{Additional file 4}

Meristic measurements for PCA of hybrids and parental species. Click here for file

[http://www.biomedcentral.com/content/supplementary/14712148-7-7-S4.doc]

\section{Additional file 5}

Factor loadings of morphometric measurements on the first three principal components of Lamprologus callipterus $(n=5)$, Neolamprologus brevis $(n=5), \mathrm{N}$. fasciatus $(n=5)$, hybrid $1(n=2)$ and hybrid $2(n=$ 2).

Click here for file

[http://www.biomedcentral.com/content/supplementary/14712148-7-7-S5.doc]

\section{Additional file 6}

Factor loadings of meristic measurements on the first three principal components of Lamprologus callipterus $(n=5)$, Neolamprologus brevis $(n=5), \mathrm{N}$. fasciatus $(n=5)$, hybrid $1(n=2)$ and hybrid $2(n=2)$. Click here for file

[http://www.biomedcentral.com/content/supplementary/14712148-7-7-S6.doc]

\section{Additional file 7}

Allele sizes of six microsatellite loci for 30 individuals representing 19 species of the "ossified group" of lamprologines.

Click here for file

[http://www.biomedcentral.com/content/supplementary/1471-

2148-7-7-S7.doc]

\section{Additional file 8}

Allele sizes of six microsatellite loci in four hybrid specimens collected at Wonzye and characterization of the genetic diversity in the parental species at the same locality, with allele size range, expected $\left(H_{e}\right)$ and observed $\left(H_{o}\right)$ heterozygosity.

Click here for file

[http://www.biomedcentral.com/content/supplementary/1471-

2148-7-7-S8.doc] 


\section{Acknowledgements}

We thank C. Kapasa and the team at the Mpulungu Station of the Department of Fisheries, Ministry of Agriculture, and Cooperatives, Republic of Zambia, for their assistance during sample collection. We are grateful to $\mathrm{H}$. Büscher and $\mathrm{L}$. Onder for providing specimens and/or tissue samples and $\mathrm{S}$. Weiss for valuable comments on earlier versions of the manuscript. We further thank $A$. Konings and $H$. Büscher for providing photographs of "ossified group" lamprologines. S.K. received a DOC fellowship and N.D. a DOC-FFORTE (Women in Research and Technology) fellowship, both provided by the Austrian Academy of Sciences. N.D. holds an ErwinSchrödinger Fellowship provided by the Austrian Science Fund. C.S. and K.M.S. were funded by the Austrian Science Foundation (Grants PI7680 and PI7380).

\section{References}

I. Salzburger W, Meyer A, Baric S, Verheyen E, Sturmbauer C: Phylogeny of the Lake Tanganyika cichlid species flock and its relationships to Central- and East African haplochromine cichlid fish faunas. Syst Biol 2002, $5 \mathrm{I}: 1 \mathrm{I}$ 13-135.

2. Poll M: Classification des cichlidae du lac Tanganika. Tribus, genres et espèces. Acad R Belg Mem Cl Sci 1986, 45: I-I63.

3. Sato T, Gashagaza MM: Shell-brooding cichlid fishes of Lake Tanganyika: their habitats and mating systems. In Fish Communities in Lake Tanganyika Edited by: Kawanabe H, Hori M, Nagoshi M. Kyoto: Kyoto University Press; 1997:219-240.

4. Büscher HH: Eigenheim aus zweiter Hand: Buntbarsche in Schneckenhäusern. DATZ - spezial issue 1998, 6:51-59.

5. Sturmbauer C, Verheyen E, Meyer A: Mitochondrial phylogeny of the Lamprologini, the major substrate spawning lineage of cichlid fishes from Lake Tanganyika in Eastern Africa. Mol Biol Evol 1994, II:691-703

6. Stiassny MLJ: A phylogenetic overview of the lamprologine cichlids of Africa (Teleostei, Cichlidae): a morphological perspective. S Afr J Sci 1997, 93:5।3-523.

7. Taborsky M: Sperm competition in fish: 'bourgeois' males and parasitic spawning. Trends Ecol Evol 1998, 13:222-227.

8. Schelly R, Salzburger W, Koblmüller S, Duftner N, Sturmbauer C Phylogenetic relationships of the lamprologine cichlid genus Lepidiolamprologus (Teleostei: Perciformes) based on mitochondrial and nuclear sequences, suggesting introgressive hybridization. Mol Phylogenet Evol 2006, 38:426-438.

9. Koblmüller S, Salzburger W, Sturmbauer C: Evolutionary relationships in the sand dwelling cichlid lineage of Lake Tanganyika suggest multiple colonization of rocky habitats and convergent origin of biparental mouthbrooding. J Mol Evol 2004, 58:79-96.

10. Koblmüller S, Duftner $\mathrm{N}$, Katongo $\mathrm{C}$, Phiri H, Sturmbauer C: Ancient divergence in bathypelagic deepwater cichlids: mitochondrial phylogeny of the tribe Bathybatini. J Mol Evol 2005, 60:297-3।4

II. Duftner N, Koblmüller S, Sturmbauer C: Evolutionary relationships of the Limnochromini, a tribe of benthic deepwater cichlid fish endemic to Lake Tanganyika, East Africa. J Mol Evol 2005, 60:277-289

12. Marijnissen SA, Michel E, Daniels SR, Erpenbeck D, Menken SB, Schram FR: Molecular evidence for recent divergence of Lake Tanganyika endemic crabs (Decapoda: Platythelphusidae). Mol Phylogenet Evol 2006, 40:628-634.

13. Cane MA, Molnar P: Closing the Indonesian seaway as a precursor to East African aridification around 3-4 million years ago. Nature 200I, 4II:157-162.

14. Konings A: Tanganyika Cichlids in Their Natural Habitat El Paso: Cichlid Press; 1998.

15. Takahashi K, Terai Y, Nishida M, Okada N: Phylogenetic relationships and ancient incomplete lineage sorting among cichlid fishes in Lake Tanganyika as revealed by analysis of the insertion of retroposons. Mol Biol Evol 200I, I 8:2057-2066.

16. McCracken KG, Sorenson MD: Is homoplasy or lineage sorting the source of incongruent mtDNA and nuclear gene trees in the stiff-tailed ducks (Nomonyx-Oxyura)? Syst Biol 2005, 54:35-55.
17. Moran P, Kornfield I: Retention of ancestral polymorphism in the mbuna species flock (Pisces: Cichlidae) of Lake Malawi. Mol Biol Evol 1993, 10:1015-1029.

18. Parker A, Kornfield I: Evolution of the mitochondrial DNA control region in the mbuna (Cichlidae) species flock of Lake Malawi, East Africa. J Mol Evol 1997, 45:70-83.

19. Nagl S, Tichy H, Meyer WE, Takahata N, Klein J: Persistence of neutral polymorphisms in Lake Victoria cichlid fish. Proc Natl Acad Sci USA 1998, 95: | 4238-| 4243.

20. Van Oppen MJ, Rico C, Turner GF, Hewitt GM: Extensive homoplasy, nonstepwise mutations, and shared ancestral polymorphism at a complex microsatellite locus in Lake Malawi cichlids. Mol Biol Evol 2000, I 7:489-498.

21. Palumbi SR, Cipriano F, Hare MP: Predicting nuclear gene coalescence from mitochondrial data: the three-times rule. Evolution 200I, 55:869-868.

22. Albertson RC, MArkert JA, Danley PD, Kocher TD: Phylogeny of a rapidly evolving clade: the cichlid fishes of Lake Malawi, East Africa. Proc Natl Acad Sci USA 1999, 96:5I07-5II 0.

23. Allender C], Seehasuen O, Knight ME, Turner GF, Maclean N: Divergent selection during speciation of Lake Malawi cichlid fishes inferred from parallel radiations in nuptial coloration. Proc Natl Acad Sci USA 2003, 100: 14074-14079.

24. Seehausen O, Koetsier E, Schneider MV, Chapman LJ, Chapman CA, Knight ME, Turner GF, van Alphen HHM, Bills R: Nuclear markers reveal unexpected genetic variation and a Congolese-Nilotic origin of the Lake Victoria cichlid species flock. Proc $R$ Soc Lond B Biol Sci 2003, 270:129-37.

25. Mayr E: Animal Species and Evolution Cambridge: Harvard University Press; 1963.

26. Sturmbauer C, Hainz S, Baric S, Verheyen E, Salzburger W: Evolution of the tribe Tropheini from Lake Tanganyika: synchronized explosive speciation producing multiple evolutionary parallelism. Hydrobiologia 2004, 500:51-64.

27. Brandstätter A, Salzburger W, Sturmbauer C: Mitochondrial phylogeny of the Cyprichromini, a lineage of open-water cichlid fishes endemic to Lake Tanganyika, East Africa. Mol Phylogenet Evol 2005, 34:382-391.

28. Sturmbauer C, Verheyen E, Rüber L, Meyer A: Phylogeographic patterns in populations of cichlid fishes from rocky habitats in Lake Tanganyika. In Molecular Phylogeny of Fishes Edited by: Kocher TD, Stepien C. New York: Academic Press; 1997:97-III.

29. Sturmbauer C, Koblmüller S, Sefc KM, Duftner N: Phylogeographic history of the genus Tropheus, a lineage of rock-dwelling cichlid fishes endemic to Lake Tanganyika. Hydrobiologia 2005, 542:335-366.

30. Rüber L, Meyer A, Sturmbauer C, Verheyen E: Population structure in two sympatric species of the Lake Tanganyika cichlid tribe Eretmodini: evidence for introgression. Mol Ecol 200I, 10:1207-1225.

31. Salzburger W, Baric S, Sturmbauer C: Speciation via introgressive hybridization in East African cichlids? Mol Ecol 2002, I I:619-625.

32. Seehausen O, van Alphen JJM, Witte F: Cichlid Fish Diversity Threatened by Eutrophication That Curbs Sexual Selection. Science 1997, 277:|808-|8||.

33. Streelman JT, Gmyrek SL, Kidd MR, Kidd C, Robinson RL, Hert E, Ambali AJ, Kocher TD: Hybridization and contemporary evolution in an introduced cichlid fish from Lake Malawi National Park. Mol Ecol 2004, 13:247I-2479.

34. Seehausen O: Conservation: losing biodiversity by reverse speciation. Curr Biol 2006, 16:R334-R337.

35. Rieseberg LH: Hybrid origins of plant species. Ann Rev Ecol Syst 1997, 28:359-389.

36. Dowling TE, Secor C: The role of hybridization and introgression in the diversification of animals. Ann Rev Ecol Syst 1997, 28:593-619.

37. Smith PF, Konings A, Kornfield I: Hybrid origin of a cichlid population in Lake Malawi: implications for genetic variation and species diversity. Mol Ecol 2003, I 2:2497-2504.

38. Schliewen UK, Klee B: Reticulate sympatric speciation in Cameroonian crater lake cichlids. Front Zool 2004, I:5.

39. Seehausen O: Hybridization and adaptive radiation. Trends Ecol Evol 2004, 19:198-207.

40. Rieseberg LH, Archer MA, Wayne RK: Transgressive segregation, adaptation and speciation. Heredity 1999, 83:363-372. 
41. Sturmbauer C, Baric S, Salzburger W, Rüber L, Verheyen E: Lake level fluctuations synchronize genetic divergence of cichlid fishes in African lakes. Mol Biol Evol 200I, 18:144-154.

42. Walsh PS, Metzger DA, Higuchi R: Chelex 100 as a medium for simple extraction of DNA for PCR-based typing from forensic material. Biotechniques 1991, I0:506-5I3

43. Kocher TD, Conroy JA, McKaye KR, Staufer JR, Lockwood SF: Evolution of NADH dehydrogenase in East African cichlid fish. Mol Phylogenet Evol 1995, 4:420-432.

44. Posada $D$, Crandall KA: MODELTEST: testing the model of DNA substitution. Bioinformatics 1998, 14:817-8|8.

45. Swofford DL: PAUP* - Phylogenetic Analysis Using Parsimony and other methods, version 4.0 Sunderland: Sinauer; 2003.

46. Tamura K, Nei M: Estimation of the number of nucleotide substitutions in the control region of mitochondrial DNA in humans and chimpanzees. Mol Biol Evol 1993, 10:512-526.

47. Strimmer K, von Haeseler A: Quartet puzzling: a quartet maximum-likelihood method for reconstructing tree topologies. Mol Biol Evol 1996, 13:964-969.

48. Huelsenbeck JP, Ronquist F: MrBayes: Bayesian inference of phylogenetic trees. Bioinformatics 200I, 17:754-755.

49. Takezaki N, Rzhetsky A, Nei M: Phylogenetic test of the molecular clock and linearized trees. Mol Biol Evol 1995, 12:823-833.

50. Schmidt HA, Strimmer K, Vingron M, von Haeseler A: TREE-PUZ ZLE: maximum likelihood phylogenetic analysis using quartets and parallel computing. Bioinformatics 2002, 18:502-504.

5I. Kishino $H$, Hasegawa M: Evaluation of the maximum likelihood estimate of the evolutionary tree topologies from DNA sequence data, and the branching order in hominoidea. J Mol Evol 1989, 29:170-179.

52. Shimodeira $\mathrm{H}$, Hasegawa M: Multiple comparisons of log-likelihoods with applications to phylogenetic inference. Mol Biol Evol 1999, 16: III4-1II6.

53. Vos P, Hogers R, Bleeker M, Reijans M, van de Lee T, Hornes M, Frijters A, Pot J, Peleman J, Kuiper M: AFLP: a new technique for DNA fingerprinting. Nucleic Acid Res 1995, 23:4407-44I4.

54. Nei M, Li WH: Mathematical model for studying genetic variation in terms of restriction endonucleases. Proc Natl Acad Sci USA 1979, 76:5269-5273.

55. Van de Peer Y, de Wachter R: TREECON for Windows: a software package for the construction and drawing of evolutionary trees for the Microsoft Windows environment. Comput Appl Biosci 1994, 10:569-570.

56. Hubbs CL, Lagler KF: Fishes of the Great Lakes region. Bull Cranbrook Inst Sci 1958, 26:

57. Barel CDN, van Oijen MJP, Witte F, Witte-Maas ELM: An introduction to the taxonomy and morphology of the haplochromine Cichlidae from Lake Victoria. Neth J Zool 1977, 27:333-389.

58. Van Oppen MJH, Rico C, Deutsch TC, Turner GF, Hewit GM: Isolation and characterization of microsatellite loci in the cichlid fish Pseudotropheus zebra. Mol Ecol 1997, 6:387-388.

59. Zardoya R, Vollmer DM, Craddock C, Streelman JT, Karl S, Meyer A: Evolutionary conservation of microsatellite flanking regions and their use in resolving the phylogeny of cichlid fishes (Pisces: Perciformes). Proc R Soc Lond B 1996, 263:1589-1598.

60. Kellogg KA, Markert JA, Stauffer JR, Kocher TD: Microsatellite analysis demonstrates multiple paternity in lekking cichlid fishes from Lake Malawi, Africa. Proc R Soc Lond B 1995 , 260:79-84.

61. Carleton KL, Streelman JT, Lee BY, Garnhart N, Kidd M, Kocher TD: Rapid isolation of CA microsatellites from the tilapia genome. Anim Genet 2002, 33: I40-I44.

62. Duftner N, Sefc KM, Koblmüller S, Nevado B, Verheyen E, Phiri H, Sturmbauer C: Distinct population structure in a phenotypically homogeneous rock-dwelling cichlid fish from Lake Tanganyika. Mol Ecol 2006, I 5:238I-2395.

63. Bills R, Ribbink Al: Description of Lamprologus laparogramma sp. nov., and rediagnosis of Lamprologus signatus Poll 1956 and Lamprologus kungweensis Poll with notes on their ecologs and behaviour (Teleostei: Cichlidae). S Afr J Sci 1952 93:555-564

64. Kuwamura $\mathrm{T}$ : The evolution of parental care and mating systems among Tanganyikan cichlids. In Fish Communities in Lake Tanganyika Edited by: Kawanabe H, Hori M, Nagoshi M. Kyoto: Kyoto University Press; 1997:57-86.
65. Konings A: Das Back to Nature Handbuch für Tanganjika-Buntbarsche 2nd edition. Ettlingen: Dähne Verlag GmBH; 2005.
Publish with Bio Med Central and every scientist can read your work free of charge

"BioMed Central will be the most significant development for disseminating the results of biomedical research in our lifetime. "

Sir Paul Nurse, Cancer Research UK

Your research papers will be:

- available free of charge to the entire biomedical community

- peer reviewed and published immediately upon acceptance

- cited in PubMed and archived on PubMed Central

- yours - you keep the copyright
BioMedcentral 